\title{
Frequency-dependent cannabinoid receptor-independent modulation of glycine receptors by endocannabinoid 2-AG
}

\author{
Natalia Lozovaya ${ }^{1 \dagger}$, Marat Mukhtarov ${ }^{2 \dagger}$, Timur Tsintsadze ${ }^{1}$, Catherine Ledent $^{3}$, Nail Burnashev ${ }^{1 \ddagger}$ and \\ Piotr Bregestovski ${ }^{2 \neq *}$
}

1 INSERM U901, Institut de Neurobiologie de la Méditerranée, Marseille, France

2 INSERM U751, Epilepsy and Cognition, Université de la Méditerranée, Marseille, France

${ }^{3}$ Institut de Recherche Interdisciplinaire en Biologie Humaine et Moléculaire, Université libre de Bruxelles, Bruxelles, Belgium

Edited by:

Bernard Attali, Tel Aviv University, Israel

\section{Reviewed by:}

Juan Lerma, Instituto de

Neurociencias, Campus de San Juan,

Spain

Erwin Sigel, University of Bern,

Switzerland

\section{${ }^{*}$ Correspondence:}

Piotr Bregestovski, INSERM U751,

27 Boulevard Jean Moulin,

13385 Marseille Cedex 05, France.

e-mail: piotr.bregestovski@univmed.fr

${ }^{\dagger}$ Natalia Lozovaya and Marat

Mukhtarov have contributed equally

to this work.

${ }^{\ddagger}$ Nail Burnashev and Piotr

Bregestovski share the last authorship.
Endocannabinoids are known as retrograde messengers, being released from the postsynaptic neuron and acting on specific presynaptic G-protein-coupled cannabinoid (CB) receptors to decrease neurotransmitter release. Also, at physiologically relevant concentrations cannabinoids can directly modulate the function of voltage-gated and receptoroperated ion channels. Using patch-clamp recording we analyzed the consequences of the direct action of an endocannabinoid, 2-arachidonoylglycerol (2-AG), on the functional properties of glycine receptor channels (GlyRs) and ionic currents in glycinergic synapses. At physiologically relevant concentrations $(0.1-1 \mu \mathrm{M}), 2-\mathrm{AG}$ directly affected the functions of recombinant homomeric $\alpha 1 \mathrm{H}$ GlyR: it inhibited peak amplitude and dramatically enhanced desensitization. The action of 2-AG on GlyR-mediated currents developed rapidly, within $\sim 300 \mathrm{~ms}$. Addition of $1 \mu \mathrm{M} 2-\mathrm{AG}$ strongly facilitated the depression of glycine-induced currents during repetitive $(4-10 \mathrm{~Hz})$ application of short $(2 \mathrm{~ms}$ duration) pulses of glycine to outside-out patches. In brainstem slices from CB1 receptor knockout mice, 2-AG significantly decreased the extent of facilitation of synaptic currents in hypoglossal motoneurons during repetitive $(10-20 \mathrm{~Hz})$ stimulation. These observations suggest that endocannabinoids can modulate postsynaptic metaplasticity of glycinergic synaptic currents in a CB1 receptor-independent manner.

\section{INTRODUCTION}

Cannabinoids have widespread actions in the brain: they influence learning and memory, modulate locomotor activity and reward pathways. Majority of its effects suggested to be mediated by specific G-protein-coupled cannabinoid receptors (CBRs), their endogenous ligands (endocannabinoids) and the cellular machinery for their synthesis and degradation. Endocannabinoids are thought to act as retrograde messengers, being released from the postsynaptic neuron and acting on presynaptic CBRs to decrease neurotransmitter release (Wilson and Nicoll, 2001). However, numerous studies have reported the existence of functionally important target(s) for brain cannabinoid signaling in addition to CBRs. These include various voltage- and ligand-gated ion channels and in particular, the Cys-loop receptor superfamily, namely the nicotinic, the serotonin and the glycine (GlyR) receptors (for review see $\mathrm{Oz}, 2006$ ). Nevertheless, the functional implications of the direct effects of endocannabinoids are poorly studied.

Of the two main endocannabinoids, anandamide and 2arachidonoylglycerol (2-AG), the later is present in brain in

Abbreviations: 2-AG, 2-arachidonoylglycerol; ACSF, artificial cerebrospinal fluid; $\mathrm{CB} 1 \mathrm{R}^{-1-}$ mice, $\mathrm{CB} 1$ receptor knockout mice; CBRs, cannabinoid receptors; CHO cells, chinese hamster ovary cells; CNQX, 6-cyano-2,3-dihydroxy-7-nitroquinoxaline; CNS, central nervous system; GABA, gamma-aminobutyric acid; GlyR, glycine receptor; HM, hypoglossal motoneurons; $I_{\mathrm{GlyR}}$, glycine-induced current. amounts of $>100$ times greater than anandamide (Stella et al., 1997). We therefore examined here direct effects of 2-AG on glycinergic synapses.

The GlyRs are highly expressed in retina, spinal cord, brainstem and some higher brain areas of vertebrates, including ventral tegmental area, nucleus accumbens, and cerebellum (Sato et al., 1991; Wassle et al., 1998; Lynch, 2009). GlyRs form chlorideselective channels and mediate fast inhibitory synaptic transmission (Legendre, 2001). These receptors are implicated in pain sensation, respiratory rhythms, motor coordination, and development (Lynch, 2004; Lynch and Callister, 2006). Their function is pivotal in maintaining the balance between excitation and inhibition of cells in response to motor and sensory stimuli (Becker, 1990).

Adult GlyRs are composed of channel-forming $\alpha_{1-4}$ and $\beta$ subunits involved in receptor anchoring (Meyer et al., 1995) to form hetero-oligomeric complexes $(3 \alpha: 2 \beta$; Betz and Laube, 2006). Only $\alpha$ subunits form functional homomeric channels that contain binding sites for agonists and competitive antagonists (Grenningloh et al., 1990; Pribilla et al., 1992; Handford et al., 1996). Various GlyR $\alpha_{1-4}$ subunit isoforms are expressed in distinct regional patterns in the CNS and are developmentally regulated (Takahashi et al., 1992; Morales et al., 1994; Betz and Laube, 2006; Wassle et al., 2009; Delaney et al., 2010). 
In hypoglossal nucleus glycinergic synapses provide the main inhibitory drive regulating respiratory activity and other physiological functions (Peever et al., 2001). Glycinergic synaptic currents in hypoglossal motoneurons (HM) are partially modulated presynaptically through the retrograde cannabinoid signaling pathway (Mukhtarov et al., 2005), while the existence of additional postsynaptic modulation of glycinergic synapses in these motoneurons has also been suggested.

Indeed, recent data indicate that cannabinoids directly modulate GlyR. The nature of this modulation depends on concentration of glycine. At low doses of the glycine $\left(<\mathrm{EC}_{30}\right)$, cannabinoids augment GlyR-induced currents $\left(I_{\mathrm{Gly}}\right)$, while suppress at high concentrations of glycine (> $\mathrm{EC}_{50}$; Lozovaya et al., 2005; Hejazi et al., 2006; Iatsenko et al., 2007; Yang et al., 2008; Zhang and Xiong, 2009). Thus cannabinoids exert dual concentration-dependent effects on $I_{\mathrm{Gly}}$.

In this study, firstly we analyzed the basic properties of direct modulation by 2-AG of homomeric $\alpha 1 \mathrm{H}$ GlyRs expressed in chinese hamster ovary $(\mathrm{CHO})$ cells that do not contain endogenous CBRs. Secondly, we showed the functional significance of direct endocannabinoid-induced modulation for the glycinergic synaptic transmission in HMs in brainstem slices from CB1R-knockout mice.

\section{MATERIALS AND METHODS}

The experiments were carried out on cultured $\mathrm{CHO}$ cell lines and on brainstem slices from postnatal (P15-P20) CB1R-knockout $\left(\mathrm{CB}_{1} \mathrm{R}^{-/-}\right)$mice (Ledent et al., 1999).

\section{CELL CULTURE AND TRANSFECTIONS}

The CHO cells were cultivated as described earlier (Fucile et al., 1999; Medina et al., 2000; Markova et al., 2008). Cells were transfected with cDNA encoding the human GlyR $\alpha 1$ subunit using the lipofectamine-reagent+ method (Life Technology, USA). To facilitate identification of transfected cells, cells were cotransfected with GFP.

\section{ELECTROPHYSIOLOGICAL RECORDINGS FROM CHO CELLS}

Glycine-activated currents were studied in the whole-cell and outside-out patch-clamp configurations using an EPC-9 amplifier (HEKA Electronics, Lambrecht, Germany) under visualization with a Nikon microscope. The experiments were performed at room temperature $\left(20-22^{\circ}\right)$ at a holding potential of $-30 \mathrm{mV}$.

The cells were incubated in solution of the following composition (in $\mathrm{mM}$ ): $140 \mathrm{NaCl}, 2.8 \mathrm{KCl}, 2 \mathrm{CaCl}_{2}, 4 \mathrm{MgCl}_{2}, 20$ HEPES/NaOH, 10 glucose, $\mathrm{pH}$ 7.4. The patch pipettes were filled with a solution containing (in $\mathrm{mM}$ ): $140 \mathrm{CsCl}, 2 \mathrm{MgCl}_{2}, 2 \mathrm{MgATP}$, $0.4 \mathrm{Na}_{2} \mathrm{GTP}, 10 \mathrm{HEPES} / \mathrm{CsOH}, 20 \mathrm{BAPTA} / \mathrm{KOH}, 6 \mathrm{CaCl}_{2}$, pH 7.2, 290-300 mOsm. For rapid replacement of solutions, a system of three parallel rectangular tubes, $100 \mu \mathrm{m}$ in diameter, located at a distance of $40-50 \mu \mathrm{m}$ from the tested cell, was used. The position of tubes was controlled by a computer regulating the fast perfusion system (SF 77A Perfusion Fast-Step; Warner, USA). As measured by open tip electrode controls $(1 / 10 \mathrm{NaCl})$, in this system a $20-80 \%$ solution exchange time was within $3 \mathrm{~ms}$ ).

For experiments mimicking synaptic release concentration, steps of glycine lasting 1-2 ms were applied to outside-out patches at various frequencies depending on the purpose of the experiment. Solution exchange across the tip of the patch pipette was performed using a piezoelectric fast application system (P 245.70, Physik Instrumente, Waldbronn, Germany). With an open tip patch electrode (resistance $>5 \mathrm{M} \Omega$ and a tip diameter $<1 \mu \mathrm{m}$ ) the estimated $20-80 \%$ exchange time was $0.1-0.2 \mathrm{~ms}$. In these experiments standard outside-out recordings were made under direct visualization (Leica microscope) of the CHO cells transfected by cDNA encoding the human GlyR $\alpha 1$ subunit. The resistance of the pipettes was 7-8 M $\Omega$ for outside-out recordings. Only outside-out patches with an input resistance exceeding $1 \mathrm{G} \Omega$ for were selected for analysis.

\section{SLICE PREPARATION}

CB1R-knockout $\left(\mathrm{CB} 1 \mathrm{R}^{-/-}\right)$mice $(\mathrm{P} 15-\mathrm{P} 20)$ were anaesthetized with either and killed by decapitation in agreement with the European Directive 86/609/EEC requirements. The brainstem was rapidly removed and placed in an oxygenated ice-cold saline buffer. Transverse $200 \mu \mathrm{m}$-thick brainstem slices were cut using an HM $650 \mathrm{~V}$ (Microm, Germany) vibrating microslicer in ice-cold protecting solution containing (in $\mathrm{mM}$ ): $130 \mathrm{~K}$-gluconate, $14.6 \mathrm{KCl}$, 2 EGTA, 20 HEPES, 25 glucose, and 0.05 D-APV, equilibrated at $\mathrm{pH} 7.3$ with $\mathrm{KOH}$. Prior to recording, slices were incubated in an ACSF solution containing (in $\mathrm{mM}$ ): $125 \mathrm{NaCl}, 3.5 \mathrm{KCl}, 2 \mathrm{CaCl}_{2}$, $1.3 \mathrm{MgCl}_{2}, 1.25 \mathrm{NaH}_{2} \mathrm{PO}_{4}, 26 \mathrm{NaHCO}_{3}$, and 10 glucose, equilibrated at $\mathrm{pH} 7.3$ with $95 \% \mathrm{O}_{2}$ and $5 \% \mathrm{CO}_{2}$ at room temperature $\left(22-25^{\circ} \mathrm{C}\right)$ for at least $1 \mathrm{~h}$ to allow recovery.

\section{ELECTROPHYSIOLOGICAL RECORDINGS IN BRAIN SLICES}

For patch-clamp recordings brainstem acute slices were visualized through a $\times 40$ water-immersion objective using an upright microscope (Axioskop, Zeiss, Germany). HM were identified by their location in the hypoglossal nucleus (n.XII), their large somata (25-40 $\mu \mathrm{m})$ and their dendritic arborization.

During measurements, slices were superfused with oxygenated saline $\left(1.0-1.5 \mathrm{ml} \mathrm{min}^{-1}\right)$ with the same ionic composition as that used for slice incubation. Borosilicate glass patch pipettes (Harvard Apparatus) with a tip resistance of 3-5 $\mathrm{M} \Omega$ were filled with an intracellular solution containing (in $\mathrm{mM}$ ): $140 \mathrm{CsCl}, 2 \mathrm{MgCl}_{2}$, $0.03 \mathrm{CaCl}_{2}, 0.1$ BAPTA, 10 HEPES, $2 \mathrm{MgATP}, 0.4 \mathrm{Na}_{2} \mathrm{GTP}$, and $10 \mathrm{Na}_{2}$-phosphocreatine, equilibrated at $\mathrm{pH} 7.3$ with $\mathrm{CsOH}, 290$ mOsm. QX 314 (1 mM) was routinely added into the intracellular solution to block voltage-gated sodium conductances.

Membrane currents were recorded with an EPC-9 (HEKA Elektronik, Germany) amplifier and filtered at $3-10 \mathrm{kHz}$. Stored data were analyzed using pClamp software (Axon Instruments) or the PulseFit program (HEKA Elektronik). The series resistances, ranging between 5 and $15 \mathrm{M} \Omega$ as estimated from slow transient cancelation, were compensated by $30-80 \%$ depending on the cell. The holding potential $\left(V_{\mathrm{h}}\right)$ was $-70 \mathrm{mV}$. The postsynaptic currents were elicited by stimulating pulses $(1-90 \mathrm{~V}, 100 \mu \mathrm{s})$ with glass bipolar electrodes. The stimulus intensity was adjusted to obtain the evoked responses without failures. Stimulating electrodes were obtained by pulling theta-glass tubes to a final tip diameter of 1$2 \mu \mathrm{m}$ and filling with external solution. Trains of 10 stimuli at 10 or $20 \mathrm{~Hz}$ were applied.

To isolate strychnine-sensitive glycinergic synaptic currents all experiments were performed in the presence of blockers of glutamate (CNQX, $10 \mu \mathrm{M} ; \mathrm{D}-\mathrm{APV}, 40 \mu \mathrm{M})$ and GABA 
(bicuculline, $10 \mu \mathrm{M}$ ) receptors. Antagonists were bath-applied via a gravity-driven perfusion system. For external application, 2-AG (5-10 $\mu \mathrm{M})$ was applied via a puff pipette close to the cell soma.

D-APV, bicuculline and 2-AG were from Tocris (UK). All the other chemicals were from Sigma (USA).

Statistical analysis was done in Origin (OriginLab Corporation, USA) using Student's paired $t$-test. Results are given as mean \pm SEM.

\section{RESULTS}

\section{DIRECT MODULATION OF GIYR $\alpha$ 1H-MEDIATED CURRENTS BY THE} ENDOCANNABINOID 2-AG

Application of glycine $(10 \mu \mathrm{M}-1 \mathrm{mM})$ to $\mathrm{CHO}$ cells transfected with $\alpha 1 \mathrm{H}$ GlyR cDNA elicited whole-cell chloride currents $\left(I_{\mathrm{GlyR}}\right)$, which exhibited weak desensitization even at a saturating concentration of agonist. The half-effective concentration of glycine $\left(\mathrm{EC}_{50}\right)$ estimated from the dose-response curve was in the range
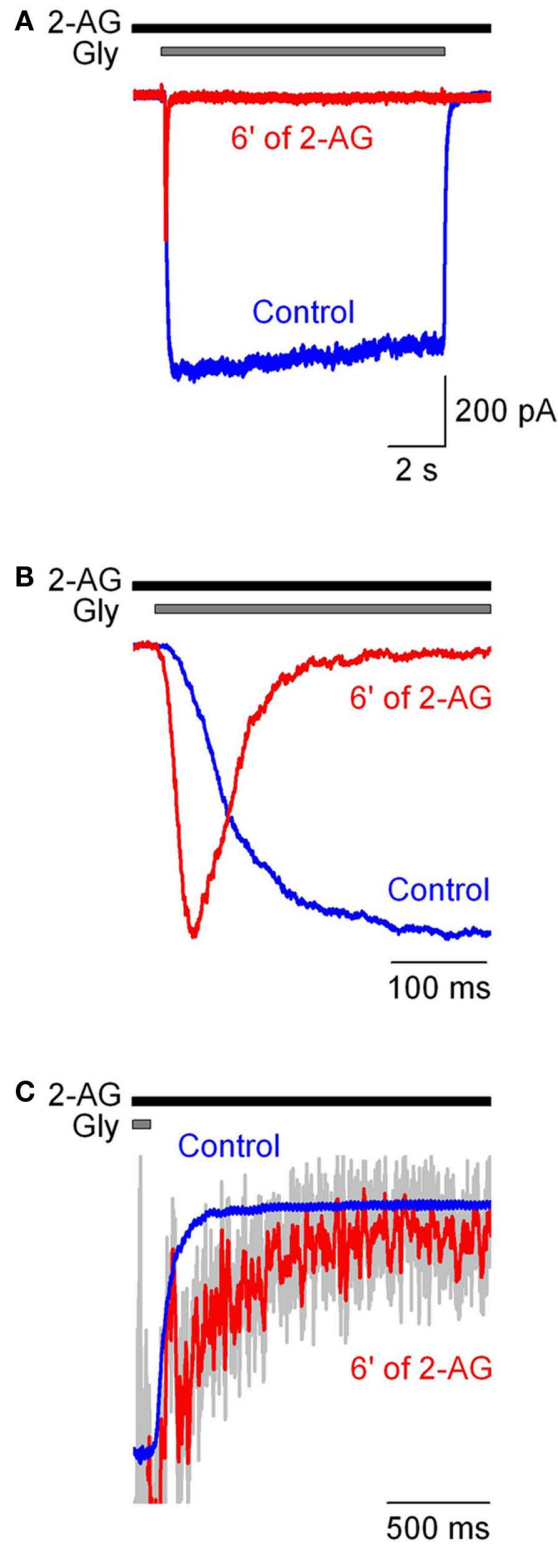

FIGURE 1 | Modulation of human GlyR $\alpha 1 \mathrm{H}$-mediated currents by 2-AG in outside-out patches. (A) Representative traces of $I_{\text {Gly }}$, induced by $50 \mu \mathrm{M}$ Gly, recorded in outside-out patch-clamp configuration in control (blue) and in the presence of $1 \mu \mathrm{M} 2-A G$ (red). Here and below representative traces correspond to the saturation of the effects of 2-AG (B) Superimposed and normalized traces shown in (A) at expanded time scale to illustrate 2-AG-induced changes in the rise time of $I_{\text {Gly }}$.
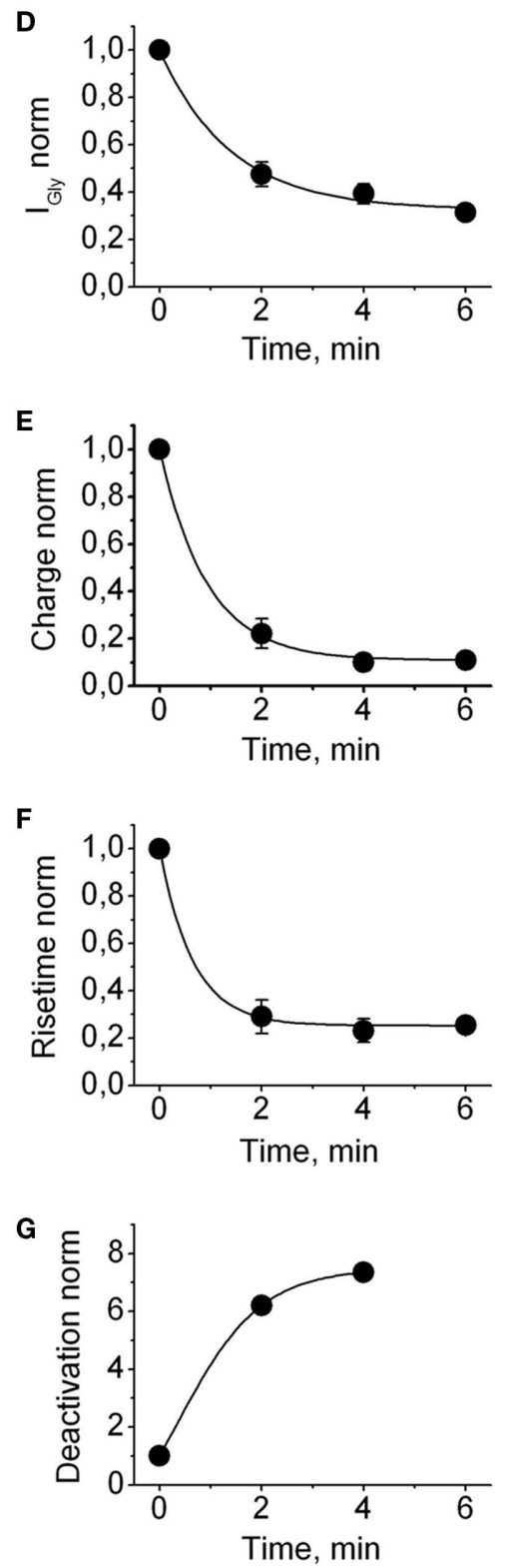

(C) Deactivation of $I_{\text {Gly }}$. Traces shown in (A) superimposed and normalized by the current amplitude at the end of glycine application before (blue) and after addition of 2-AG (gray; the same trace smoothed by Savitzky-Golay method is shown in red). (D-G) Time courses of the changes in $I_{\text {Gly }}$ peak amplitude (D), charge transfer of $I_{\text {Gly }}$ normalized by peak amplitude (E), 10-90\% rise time (F), and $10-90 \%$ deactivation time (G) following application of $1 \mu \mathrm{M} 2-\mathrm{AG}$. 
40-70 $\mu \mathrm{M}$ (data not shown), which corresponds closely to previously reported values in cell lines expressing $\alpha 1$ GlyR (Fucile et al., 1999, 2000; Buldakova et al., 2007; Markova et al., 2008). These values are also similar to those reported for acutely isolated rat hippocampal neurons (Kondratskaya et al., 2002) and for other preparations (Chesnoy-Marchais, 2003; Ge et al., 2007).

Effects of the endogenous cannabinoid 2-AG on $I_{\mathrm{GlyR}}$ were studied in outside-out patches pulled from $\mathrm{CHO}$ cells transfected with $\alpha 1 \mathrm{H}$ GlyR cDNA. GlyR-mediated chloride currents $\left(I_{\mathrm{GlyR}}\right)$ were evoked by application of $10 \mathrm{~s}$-long pulses of $50 \mu \mathrm{M}$ glycine (concentration close to $\mathrm{EC}_{50}$ ). After control recordings, cells were exposed to the external solution with $2-A G(1 \mu \mathrm{M})$ and $2 \mathrm{~min}$ later $I_{\mathrm{GlyR} \alpha}$ were recorded every $2 \mathrm{~min}$ in the continuous presence of 2-AG. Figure 1 shows that continuous application of 2-AG caused dramatic effects on glycine-induced currents. It inhibited the peak, decreased the rise time, strongly accelerated the rate of desensitization and slowed down the deactivation of $I_{\mathrm{GlyR}}$. Effects reached saturation within 3-6 min. A particularly dramatic effect was on the kinetics of desensitization, which accelerated by hundreds of times. For instance, in the patch presented in Figure 1, the half time of current decay is less than $50 \mathrm{~ms}$ after $6 \mathrm{~min}$ of 2-AG application. All the effects of 2-AG were partially reversible (Figures 2A-C). To quantify the effects of $1 \mu \mathrm{M} 2-\mathrm{AG}$ we calculated averaged $I_{\mathrm{GlyR}}$ peak amplitudes, charge transfer of $I_{\mathrm{GlyR}}$ normalized by peak amplitude (reflecting changes in the speed of desensitization) and $10-90 \%$ rise time and deactivation time values in the presence of $2-\mathrm{AG}$, and compared these with control values.

After 4-6 min of the presence of 2-AG, mean peak amplitude values, calculated as $I_{2-\mathrm{AG}} / I_{\mathrm{CTRL}}$, decreased to $0.35 \pm 0.04$ $(p=0.0001 ; n=9)$. Charge transfer of $I_{\mathrm{GlyR}}$ normalized by peak amplitude, used as an index of desensitization of $I_{\mathrm{GlyR}}$, decreased to $0.066 \pm 0.01 \quad(p<0.0001 ; n=9)$. The rise time strongly decreased while deactivation time increased, with mean values of, respectively, $0.18 \pm 0.02(p<0.004 ; n=9)$, and $3.64 \pm 0.87$ $(p=0.03, n=4)$ relative to control (Figure $2 \mathrm{C}$ ).

The effects of 2-AG on $I_{\mathrm{GlyR}}$ depended on the concentration of endocannabinoid and were significant starting from $100 \mathrm{nM}$ of 2-AG (Figures 2D,E). After $6 \mathrm{~min}$ of $100 \mathrm{nM} 2-\mathrm{AG}$ application, the mean peak amplitude of glycine-induced currents decreased to $0.68 \pm 0.04(p<0.02 ; n=5)$, normalized charge transfer by $I_{\mathrm{GlyR}}$ decreased to $0.55 \pm 0.12(p<0.002 ; n=5)$ of control and $I_{\mathrm{GlyR}}$ rise time decreased to $0.61 \pm 0.05(p<0.005 ; n=5)$ of control.

To estimate the rate of interaction of 2-AG with GlyR in outside-out patches we tested the modulation of $I_{\mathrm{GlyR}}$ by 2AG $(1 \mu \mathrm{M})$ applied simultaneously with glycine. Under these conditions the peak amplitude and the rise time of $I_{\mathrm{GlyR}}$ were unaltered; however, the normalized charge transfer decreased to $0.59 \pm 0.02(p<0.02 ; n=3$; Figure 3$)$. Changes in $I_{\mathrm{GlyR}}$ desensitization kinetics were first detected at $264 \pm 65 \mathrm{~ms}$ from the beginning of co-application of glycine and 2-AG $(n=5$; Figure 3).

These observations demonstrate that the endocannabinoid 2AG modulates GlyR function by a CBR-independent mechanism, as $\mathrm{CHO}$ cells do not endogenously express any CBR. The effects developed in the time scale of hundreds milliseconds.

\section{EFFECTS OF 2-AG ON CURRENTS MEDIATED BY GIYR $\alpha 1 \mathrm{H}$ DEPENDED ON AGONIST CONCENTRATION}

Several studies have shown that the modulatory effects of cannabinoids on GlyRs depend on the glycine concentration used for receptor activation (Hejazi et al., 2006; Yang et al., 2008). Therefore, we tested whether modulation of $I_{\mathrm{GlyR}}$ by $2-\mathrm{AG}(1 \mu \mathrm{M})$ was dependent on the concentration of the agonist. Three concentrations of glycine were tested: low $(20 \mu \mathrm{M})$, half-effective $(50 \mu \mathrm{M})$, and saturating $(1 \mathrm{mM})$. Figure 4 shows that the maximal effects of $2-\mathrm{AG}$ on $I_{\mathrm{GlyR}}$ peak and charge transfer were reached at $50 \mu \mathrm{M}$ of glycine. $I_{\mathrm{GlyR}}$ induced by low and saturating glycine concentrations was significantly less affected by $2-A G$, resulting in a bell-shaped glycine concentration dependence (Figure 4D). $I_{\mathrm{GlyR}}$ induced by $50 \mu \mathrm{M}$ of glycine in the presence of $2-\mathrm{AG}$ was inhibited to $0.35 \pm 0.04(p=0.0001, n=9)$, while $I_{\mathrm{Gly}}$ evoked by $20 \mu \mathrm{M}$, and $1 \mathrm{mM}$ in the presence of 2-AG were either not affected or affected to a much lesser extent $(1.04 \pm 0.06, p=0.52, n=4$ and $0.8 \pm 0.08, p=0.03, n=4$, respectively). Normalized charge transfer of $I_{\mathrm{GlyR}}$ induced by $50 \mu \mathrm{M}$ glycine in the presence of $2-\mathrm{AG}$ decreased to $0.07 \pm 0.02, p=0.0001$, while normalized charges of $I_{\mathrm{GlyR}}$ induced by $20 \mu \mathrm{M}$ and $1 \mathrm{mM}$ were less affected $(0.31 \pm 0.10$, $p=0.001, n=4$ and $0.16 \pm 0.05, p=0.001, n=4$, respectively). It should be specifically noted that when measured in the whole-cell configuration 2-AG induced potent augmentation of $I_{\mathrm{Gly}}$ induced by a low concentration of glycine $20 \mu \mathrm{M}$ (data not shown). This is in agreement with previous papers on the effects of cannabinoids on GlyR (Hejazi et al., 2006; Iatsenko et al., 2007; Yang et al., 2008; Zhang and Xiong, 2009), while in outside-out configuration (as indicated above) this facilitation was not apparent. This difference could be a result of the distortion of the cytoskeleton and/or more efficient wash-out of intracellular factors in the outside-out patches that might be involved in up-regulation of GlyR by 2-AG. However, in the present paper we did not focus on this issue.

\section{FREQUENCY-DEPENDENT MODULATION OF $I_{\text {Gly }}$ BY ENDOCANNABINOIDS IN OUTSIDE-OUT PATCHES}

Recent study on neurons of zebrafish hindbrain suggest that the slow GlyR desensitization process mainly accounts for the frequency-dependent decrease in GlyR-mediated responses (Rigo and Legendre, 2006). We hypothesized, therefore, that the strong acceleration of GlyR desensitization induced by endocannabinoids would contribute to the reinforcement of the frequencydependent decrease in synaptic glycinergic current amplitudes.

We tested this hypothesis in outside-out patches from $\mathrm{CHO}$ cells transfected with GlyRs. Since in synapses neurotransmitter release is evoked by saturating glycine concentration, we first tested the effects of 2-AG on $I_{\mathrm{GlyR}}$ activated by $1 \mathrm{mM}$ of glycine. Figures $\mathbf{5 A}, \mathbf{B}$ shows that with long (10s) application of $1 \mathrm{mM}$ glycine 2-AG $(1 \mu \mathrm{M})$ also significantly inhibited the peak and accelerated the rate of desensitization of $I_{\mathrm{GlyR}}$ (although the effects were less strong as with $50 \mu \mathrm{M}$ glycine). The same effect of 2-AG on the peak current was observed with short $(2 \mathrm{~ms})$ ultra fast application of $1 \mathrm{mM}$ glycine mimicking synaptic transmission (Figures 5C,D). Whereas, the decay kinetics of the current representing deactivation was slightly, but not significantly increased (Figure 5C). 
A

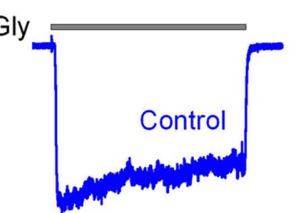

B

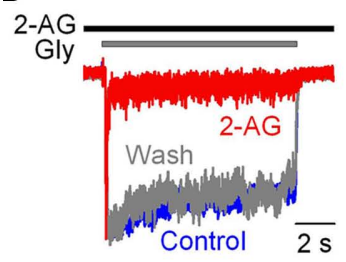

C

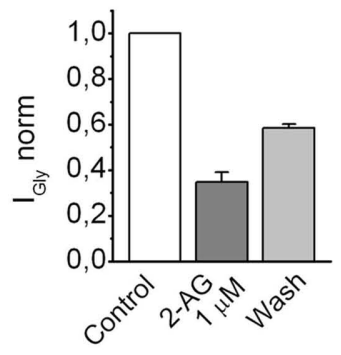

D

$\mathbf{E}$
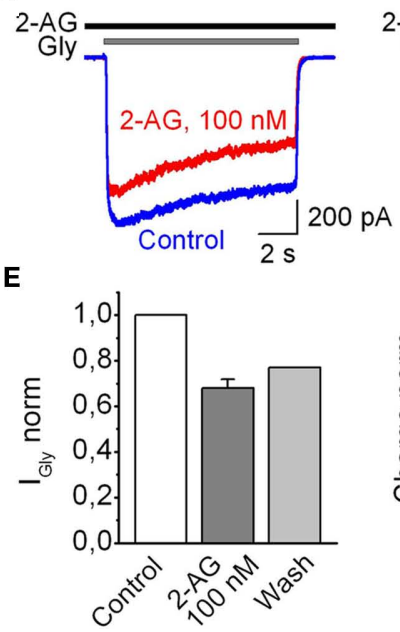

2-AG

Gly

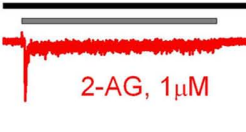

Gly

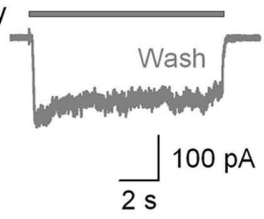

2-AG
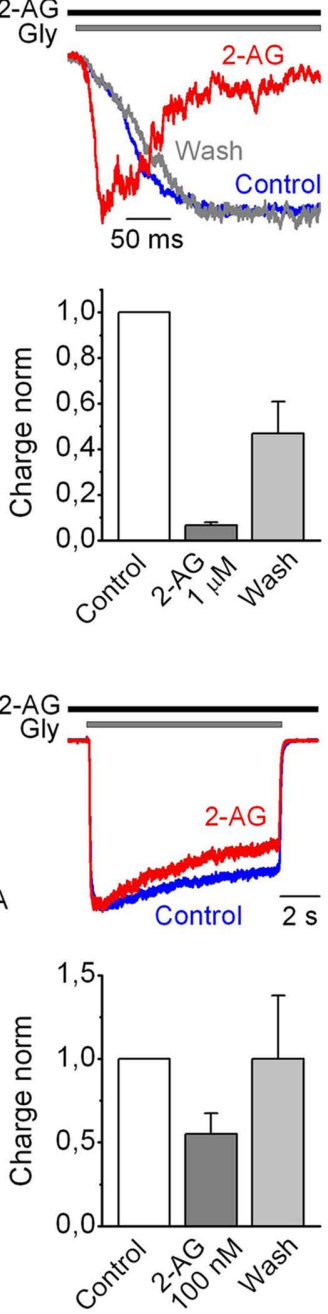

2-AG
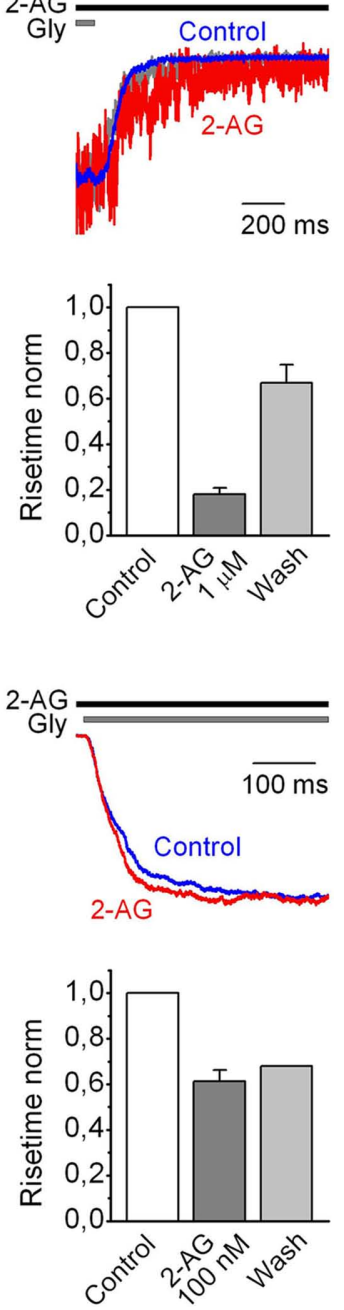

FIGURE 2 | Summary of the saturated effects of the modulation of human GlyR $\alpha 1 \mathrm{H}$-mediated currents recorded from outside-out patches by 2-AG. (A) Representative traces of $I_{\text {Gly }}$, induced by $50 \mu \mathrm{M}$ Gly, obtained in control (left), in the presence of $1 \mu \mathrm{M} 2-\mathrm{AG}$ (middle), and after wash-out of cannabinoids (right). (B) Corresponding traces are superimposed and normalized; the whole traces (left) and at expanded time scales (middle, right). (C) Mean values for changes in $I_{\text {Gly }}$ peak (left), charge transfer of $I_{\text {Gly }}$ normalized by peak amplitude (middle), and $10-90 \%$ rise time (right) induced by $2-A G$ plotted as a fraction of the control values. Data from nine outside-out patches. (D) Modulation of $I_{\text {Gly }}$ induced by $50 \mu \mathrm{M}$ Gly by a submicromolar $(100 \mathrm{nM})$ concentration of 2-AG. (Left) Representative traces obtained in control (blue) and at $100 \mathrm{nM}$ of 2-AG (red). (Middle) Corresponding traces are normalized and superimposed. (Right) The same traces at expanded time scale to illustrate 2-AG-induced changes in the rise time. (E) Summary plots showing the effects of $100 \mathrm{nM}$ of 2-AG on the amplitude (left), normalized charge (middle), and 10-90\% rise time of $I_{\text {Gly }}($ right), normalized to control values. Data from five outside-out patches.
Next we tested effects of 2-AG on $I_{\mathrm{GlyR}}$ evoked by a train of short glycine pulses using ultra fast agonist application techniques. The amplitude of the outside-out currents evoked by repetitive applications $(10 \mathrm{~Hz})$ of short $(2 \mathrm{~ms})$ pulses of a saturating glycine concentration ( $1 \mathrm{mM}$ ) progressively declined (Figure 6A). The extent of this decline increased with increasing application frequencies (not shown).

This depression of $I_{\mathrm{GlyR} \alpha 1 \mathrm{H}}$ during repetitive application of glycine was strongly enhanced in the presence of $2-\mathrm{AG}(1 \mu \mathrm{M}$; Figures $6 \mathrm{~A}-\mathrm{C}$ ). The ratios of amplitudes of the 10th and first 

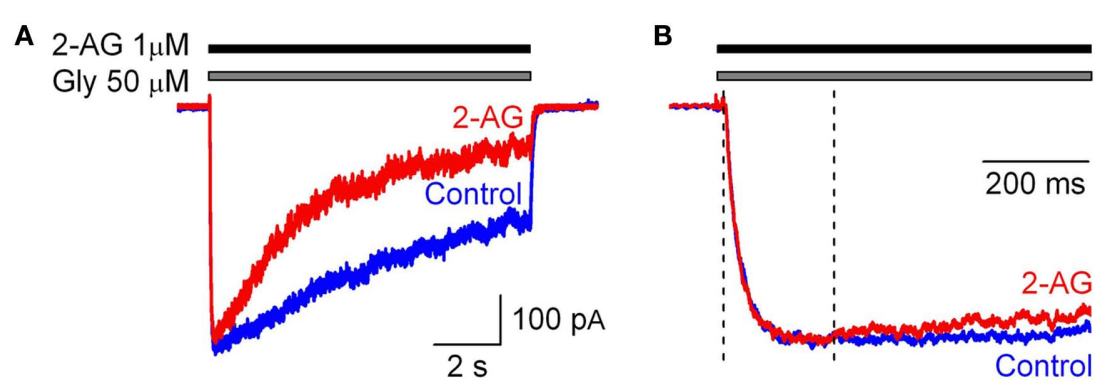

FIGURE 3 | Effect of 2-AG $(1 \mu \mathrm{M})$ on $I_{\text {Gly }}$ occurs within hundreds of milliseconds. (A) Representative traces of $I_{\text {Gly }}$ obtained in control (blue) and in the presence 2-AG $(1 \mu \mathrm{M}$, red) applied simultaneously with glycine $(50 \mu \mathrm{M})$.
(B) Corresponding traces are normalized and superimposed. Note that changes in $I_{\text {GlyR }}$ kinetics can be detected from $200 \mathrm{~ms}$ after the beginning of glycine and 2-AG co-application.

\section{A $2-A G$
$50 \mu \mathrm{M}$}

B

C

$$
2-A G
$$

Gly $20 \mu \mathrm{M}$

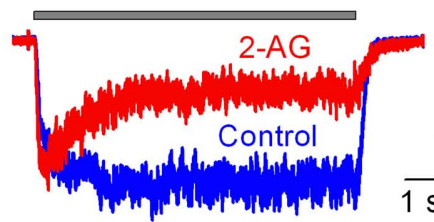

$500 \mathrm{~ms}$

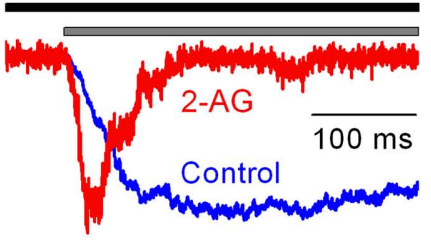

$50 \mathrm{pA}$

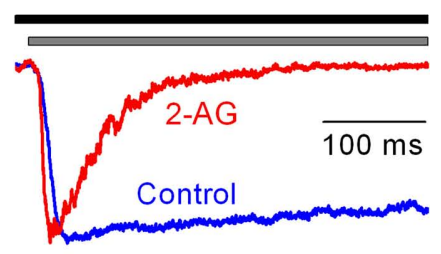

$50 \mathrm{pA}$

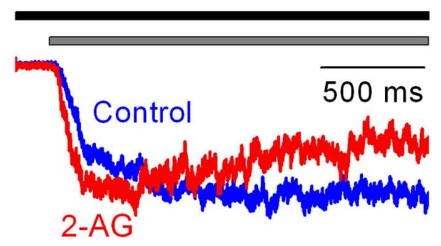

$50 \mathrm{pA}$ $\mathrm{s}$

D

FIGURE 4 | Modulation of $\boldsymbol{I}_{\mathrm{Gly}}$ by 2-AG depends on the concentration of glycine. (A-C) Left, representative outside-out recordings of $I_{\text {Gly }}$ induced by $50 \mu \mathrm{M}$ (A), $1 \mathrm{mM}$ (B), and $20 \mu \mathrm{M}$ (C) of glycine obtained in control and in the presence 2-AG $(1 \mu \mathrm{M})$. (A-C) Right, corresponding traces are normalized and
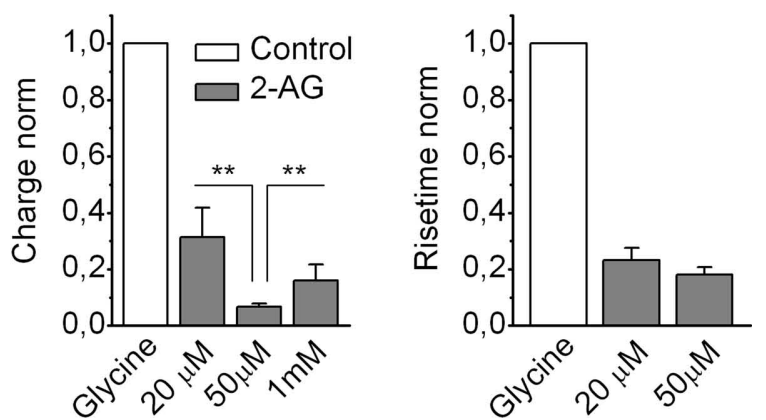
A

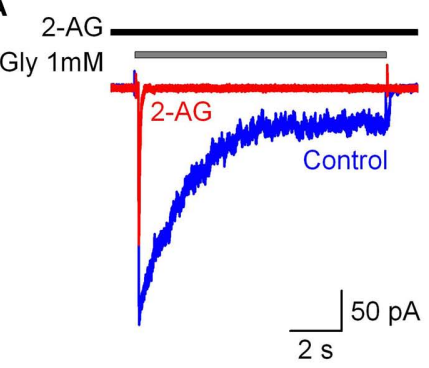

C

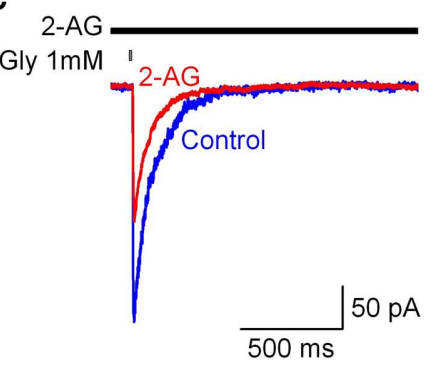

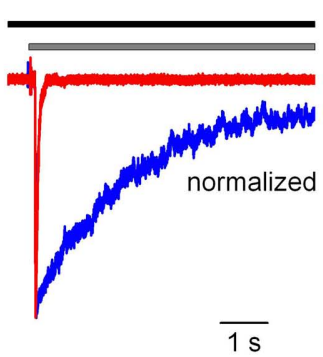

B

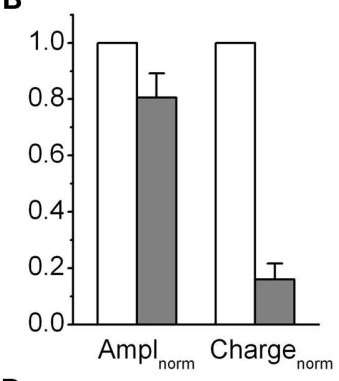

D
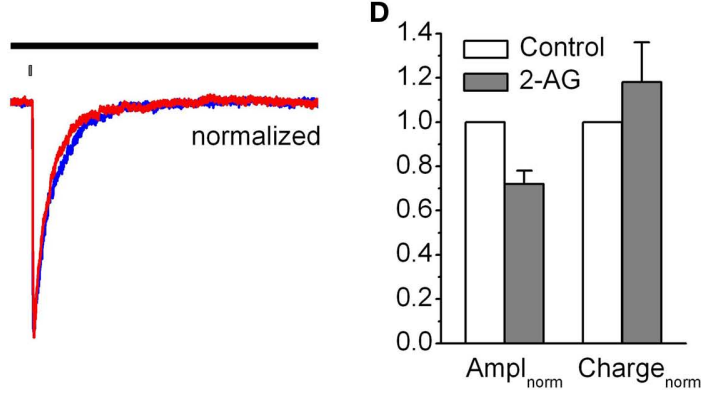

FIGURE 5 | Modulation by 2-AG of $\boldsymbol{I}_{\mathrm{GlyR}}$ evoked by saturated concentration of glycine. (A) Left, representative traces of $I_{\text {GlyR }}$ induced by long (10 s) pulse of $1 \mathrm{mM}$ Gly, obtained in control (b/ue), in the presence of $1 \mu \mathrm{M}$ 2-AG (red). Right, corresponding traces are normalized and superimposed. (B) Summary plots showing the effects of $1 \mu \mathrm{M}$ 2-AG on $I_{\text {GlyR }}$ amplitude and charge transfer of $I_{\text {Gly }}$ normalized by peak amplitude. Data are plotted as a fraction of control values. $(\mathbf{C}, \mathbf{D})$ The same as in $(\mathbf{A}, \mathbf{B})$, but for (2 $\mathrm{ms})$ pulse of $1 \mathrm{mM}$ glycine.
A

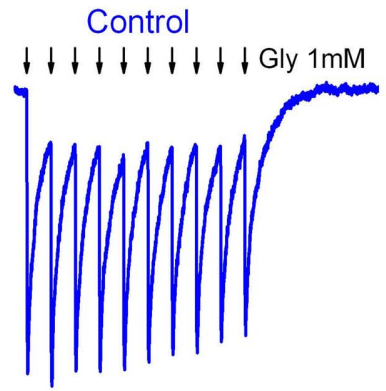

B

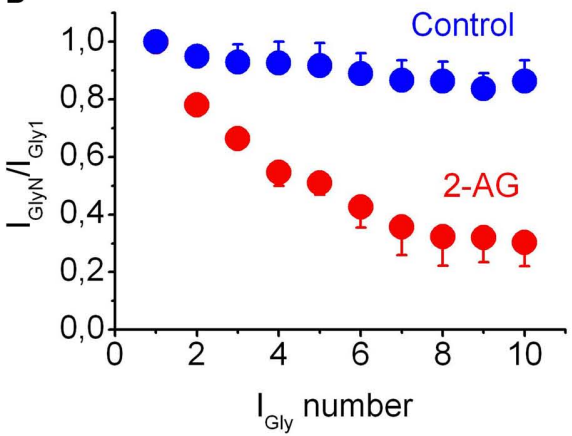

\section{$2-A G$}

$\downarrow+\downarrow \downarrow \downarrow \downarrow \downarrow \downarrow \downarrow \downarrow$

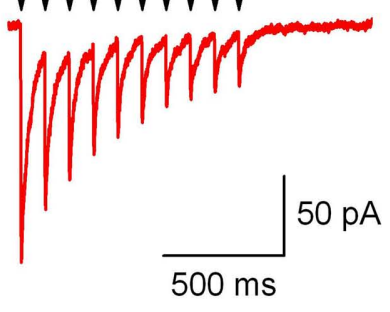

$50 \mathrm{pA}$

$500 \mathrm{~ms}$

\section{Wash}

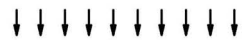
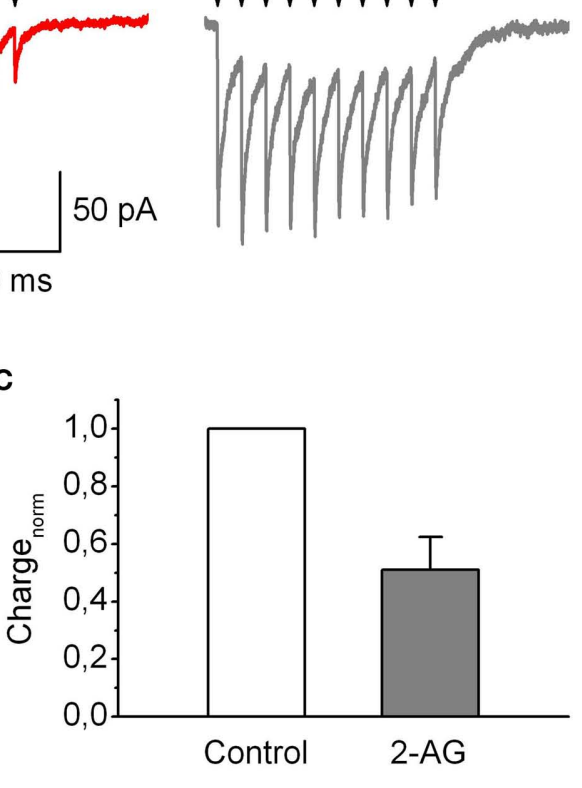

FIGURE 6 | Frequency-dependent modulation of $I_{\text {GIy }}$ by endocannabinoids in outside-out patches. (A) Representative traces of $I_{\text {Gly }}$ induced by the train $(10 \mathrm{~Hz}, 10$ pulses) of 10 short $(2 \mathrm{~ms})$ applications of Gly $(1 \mathrm{mM})$ in control (left), in the presence 2-AG $(1 \mu \mathrm{M}$; Middle), and after wash-out of 2-AG (right). Arrows indicate the glycine applications. (B)
Summary plot showing decline in $I_{\text {GIy }}$ in response to a train of stimuli, in control (blue circles) and in the presence of $1 \mu \mathrm{M}$ 2-AG (red circles). (C) Averaged total charge of $I_{\text {Gly }}$ in response to a train of stimuli normalized by first peak amplitude, in the presence of 2-AG as a fraction of control value. Data from four outside-out patches. 
currents in trains $\left(I_{\mathrm{Gly} 10} / I_{\mathrm{Glyl}}\right)$ were $0.86 \pm 0.07$ in control and $0.30 \pm 0.08$ in the presence of $2-\mathrm{AG}(p=0.003, n=4$; Figure 6B). Correspondingly, charge transfer in the train normalized to the first peak was also significantly decreased, to $0.50 \pm 0.11$ ( $p=0.006, n=4$; Figure 6C), while the absolute charge of $I_{\mathrm{GlyR}}$ induced by a train of short pulses of Gly, applied at $10 \mathrm{~Hz}$, decreased to $0.28 \pm 0.06 ; p=0.004$. The same phenomenon, but to a lesser extent, was observed at $4 \mathrm{~Hz}$ stimulation (data not shown).

These observations indicate that 2-AG can be a powerful modulator of glycinergic responses amplitude at high-frequency activation.

\section{SHORT-TERM PLASTICITY OF GLYCINERGIC TRANSMISSION INDUCED BY DIRECT ACTION OF 2-AG ON RAT HYPOGLOSSAL MOTONEURONS}

It has been suggested previously that in HMs, in addition to the CB1R-dependent retrograde signaling pathway, there exist additional mechanisms of modulation of glycinergic synaptic transmission by endocannabinoids (Mukhtarov et al., 2005). One of these mechanisms would be direct interaction of GlyRs and endocannabinoids. To test whether the direct modulation of the GlyR desensitization by endocannabinoids contributes to the activity-dependent changes in glycinergic transmission we performed experiments in HMs using the $\mathrm{CB}_{1} \mathrm{R}^{-/-}$mouse brainstem slice preparation. This model eliminates the possible impact of presynaptic retrograde modulation by endocannabinoids.
Short-term changes in glycinergic synaptic currents induced by repetitive stimulation of presynaptic axons in the presence of 2AG were investigated using whole-cell voltage-clamp recordings. In control conditions a train of repetitive stimuli applied at $20 \mathrm{~Hz}$ induced significant short-term facilitation of the glycinergic postsynaptic currents. Figure 7A shows representative averaged traces of the increased IPSCs evoked by trains. In the presence of 2-AG the extent of synaptic facilitation during the train was significantly less developed (Figures 7A,B). The ratios of amplitudes of the 10 th and first currents in trains $\left(I_{\mathrm{IPSC} 10} / I_{\mathrm{IPSC} 1}\right)$ were $1.79 \pm 0.44$ in control and $0.94 \pm 0.12$ in the presence of $2-\mathrm{AG} ; p<0.02, n=5$. Correspondingly, normalized charge transfer in the train also significantly decreased to $0.74 \pm 0.07 ; p<0.02, n=5$ (Figure 7C). The peak amplitude of the first IPSC in the train in the presence of 2 -AG was $0.64 \pm 0.15(p<0.05, n=5)$ of the control value. The same phenomena, but to a smaller extent, were observed at $10 \mathrm{~Hz}$ stimulation (data not shown).

These data directly demonstrate the physiological implications for the CB1-independent modulation of GlyR by endocannabinoids.

\section{DISCUSSION}

The key findings of the present paper are the following. First, the endocannabinoid 2-AG directly affected functions of recombinant homomeric $\alpha 1 \mathrm{H}$ GlyR: it inhibited peak amplitude, dramatically enhanced desensitization, decreased the rise time and slowed down the deactivation of $I_{\mathrm{Gly}}$ induced by a long pulse of agonist. Second,

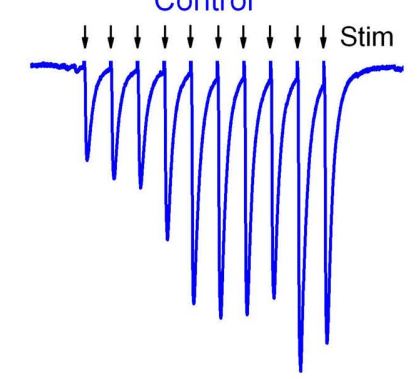

B

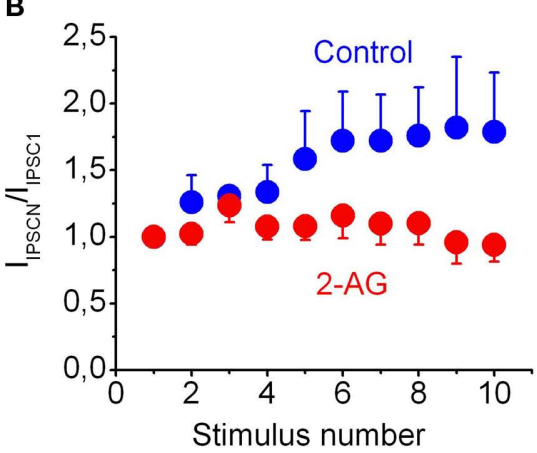

FIGURE 7 | Frequency-dependent 2-AG-induced modulation of glycinergic IPSCs recorded from hypoglossal motoneurons in the CB1R-knockout mouse brainstem slice. (A) Representative averaged trace of five individual traces of IPSC induced by presynaptic stimulation $(20 \mathrm{~Hz})$ in control (left) and in the presence 2-AG $(5 \mu \mathrm{M}$; middle). The same traces are normalized to the first peak amplitude (right).
2-AG

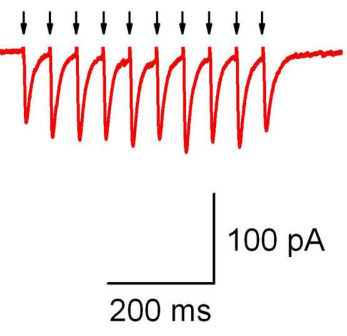

Normalized

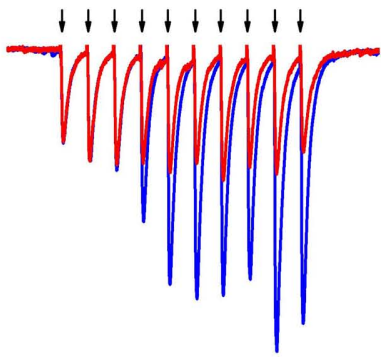

C

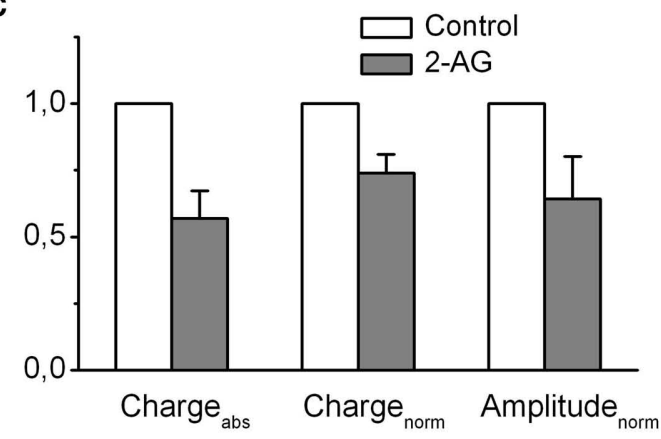

(B) Summary plot showing changes in the mean IPSC amplitudes in response to a train of stimuli, in control (blue circles) and in the presence of 2-AG (red circles). (C) Averaged absolute and normalized (by first peak $I_{\text {IPSC }}$ amplitude) charges of IPSCs in train and peak amplitude of the first IPSC in the presence of 2-AG relative to control. (B,C) Data from five experiments. 
the onset of action of 2-AG on GlyR function developed rapidly, within $300 \mathrm{~ms}$. Third, 2-AG strongly facilitated the depression of $I_{\mathrm{Gly}}$ during repetitive short ( $2 \mathrm{~ms}$ duration) pulses of glycine applied to outside-out patches and, therefore, affected activitydependent plasticity of GlyR. Fourth, in HMs in brainstem slices from $\mathrm{CB}^{-1-}$ mice, $2-\mathrm{AG}$ induced postsynaptic metaplasticity of glycinergic synapses in a CB1R-independent manner.

Our experimental data indicate that modulation of GlyR gating by 2-AG appears to be most compatible with the enhancement of GlyR sensitivity to agonist and with desensitization. 2-AG modulates recombinant GlyR at a concentration range similar to that of the 2-AG affinity for CB1Rs (60-472 nM; Mechoulam et al., 1995; Howlett et al., 2002). We had already observed significant modulation of the amplitude, activation and decay kinetics of $I_{\mathrm{Gly}}$ at a 2-AG concentration of $100 \mathrm{nM}$. Furthermore, since 2-AG, highly lipophilic compound, is believed to be synthetized and accumulated within lipid bilayer (Di Marzo et al., 1999) its concentration in the vicinity of GlyR might be much higher.

It is unlikely that the observations described here can be attributed to the activation of any known CBR. First of all, cannabinoids affected currents mediated by recombinant GlyRs expressed in $\mathrm{CHO}$ cells. Secondly, in our experiments were used CB1 knockout mice, excluding interaction with this subtype. Thirdly, the pharmacological profile of cannabinoid-induced effects on GlyRs was remarkably different from that of classical CBRs. While CB1R mediated effects can be inhibited by the antagonist SR141716A (Thomas et al., 2006), in our earlier experiments SR141716A failed to block cannabinoid induced reduction of native GlyRmediated current amplitude in isolated hippocampal neurons. In contrast SR141716A itself modulated GlyRs in a similar way as CB1R agonist. (Lozovaya et al., 2005).

Another striking difference in pharmacological profile of the two mechanisms is that the order of potency for different agonists differs from that observed for CB1R activation. WIN55,212-2 is much more potent at activating the CB1R compared to endogenous cannabinoids such as 2-AG (Breivogel et al., 2001). However, in our experiments, $2-\mathrm{AG}$ was much more potent at modulating of both recombinant alpha 1 (see Figure S1 in Supplementary Material) and native GlyR-mediated currents (Lozovaya et al., 2005).

The current decay after removal of glycine represents transitions from active ligand-bound receptor states to inactive unbound states, including channel closure and glycine dissociation. In addition, desensitized receptors may be reopened before agonist dissociation, prolonging the deactivation time course (Jones and Westbrook, 1995). The fact that endocannabinoids accelerated the $I_{\mathrm{Gly}}$ desensitization suggested the possibility of coupling between $I_{\mathrm{Gly}}$ desensitization and deactivation. Indeed, acceleration of $I_{\mathrm{Gly}}$ desensitization by $2-\mathrm{AG}$ was accompanied by a slowdown of $I_{\mathrm{Gly}}$ deactivation. This phenomenon of desensitizationdeactivation coupling has been observed in a number of experimental conditions (Jones and Westbrook, 1995; Lagrange et al., 2007). Moreover, it has been shown that desensitization shifts receptor-operated channels to a high-affinity state (Chang et al., 2002).

Our experimental data and model simulations (see Appendix) using simplified model of GlyR proposed by (Grewer, 1999) and the ChannelLab 2.0 software (developed by S. Traynelis for Synaptosoft, Decatur, GA, USA, unpublished data) indicate that modulation of GlyR gating by endocannabinoids considered here appears to be most compatible with enhancement of binding and desensitization. However, we cannot exclude that 2-AG additionally affected conformational transitions other than binding and desensitization but their impact is minor.

Thus 2-AG strongly affects parameters of $I_{\text {Gly }}$ induced by long application of glycine. However, macroscopic desensitization does not seem to contribute to GlyR function during brief agonist exposure. The question arises as to whether endocannabinoidinduced modulation of GlyR gating has implications for synaptic transmission. It has recently been suggested that the GlyR desensitization process may contribute to a frequency-dependent decrease in GlyR-mediated response amplitude (Rigo and Legendre, 2006). Indeed, our data show that modulation of GlyR by 2-AG during repetitive stimulation occurs in a strongly frequency-dependent manner and becomes prominent at $10 \mathrm{~Hz}$. Receptor activity can be down-regulated as a result of progressive accumulation of the number of postsynaptic receptors being in a long-lasting desensitization state. It has been shown that desensitization of postsynaptic AMPA and GABA receptors plays a role in short-term plasticity (STP) of synaptic transmission (for review see Zucker and Regehr, 2002). This phenomenon can be developed on elevation of the low concentration of neurotransmitter in the synaptic cleft during prolonged synaptic activation (Larkman et al., 1997; Overstreet et al., 2000) or at accumulation of a small fraction of postsynaptic receptors in a desensitized state when activation frequency is close to the recovery rate constant from the desensitized state (Rigo and Legendre, 2006). In our experiments $2-A G$ induced a dramatic increase in the fraction of desensitized GlyRs; correspondingly, this leads to an enhancement of short-term depression (STD) in a condition of repetitive stimulation.

Short-term plasticity plays an essential role in filtering sensory information (O'Donovan and Rinzel, 1997; Zucker and Regehr, 2002; Thomson, 2003; Abbott and Regehr, 2004). At the synaptic level, the efficacy of fast inhibitory synaptic transmission depends on the number of presynaptic release sites, the presynaptic release probability and the parameters of postsynaptic responses. Prominent postsynaptic alterations include modulation of desensitization. STP in turn can be modulated by previous synaptic activity or by neuromodulatory inputs. This second degree of plasticity, plasticity of plasticity, has been termed metaplasticity (Abraham and Tate, 1997; Fischer et al., 1997) and is regarded to be essential for information processing in neuronal networks (for review see Abraham and Tate, 1997; Abbott and Regehr, 2004). While persistent changes in synaptic efficacy, such as long-term potentiation and long-term depression, are essential for information storage in neural networks (Malenka and Bear, 2004), a complementary mechanism, metaplasticity, maintains network stability and ensures that synapses operate within a functional dynamic range by modifying the expression of synaptic plasticity as a function of prior activity (Abraham, 2008). Endocannabinoids are widely regarded as negative modulators of presynaptic release, acting retrogradely via presynaptic Gprotein-coupled $\mathrm{CB} 1$ receptors, and have emerged as key activitydependent signals that can mediate short-term and long-term 
synaptic depression (for a review, see (Chevaleyre et al., 2006). Retrograde endocannabinoid modulation of neurotransmitter release is well established for GABA-ergic, glutamatergic and glycinergic synaptic transmission (for review see Kano et al., 2009). Here we report that endocannabinoids may also induce metaplasticity in the inhibitory glycinergic synapses via postsynaptic mechanisms. 2-AG strongly facilitated the frequency-dependent down-regulation of GlyR as a result of a dramatic enhancement in desensitization.

Natural glycinergic synapses in hypoglossal neurons display short-term facilitation due to presynaptic mechanisms, and this facilitation is prevalent in the interplay between presynaptic and postsynaptic mechanisms of STP. In our experiments on $C B 1 \mathrm{R}^{-1-}$ mice $2-A G$ removed short-term facilitation in these synapses and even converted facilitation into depression (two out of five cases). We suggest that this is a result of an increased contribution from postsynaptically induced STD in the presence of 2-AG. The interplay of various STP components at each synapse and the dynamic interaction of the two types of synapses (excitatory and inhibitory) are thought to determine the types of computations performed by neural circuits (Tsodyks and Markram, 1997; Dobrunz and Stevens, 1999; Dittman et al., 2000; Pouille and Scanziani, 2004). STD has been postulated to be essential in the regulation of many cognitive functions including habituation (Chung et al., 2002; Nicolelis, 2002) and coordination of motor control (Nadim and Manor, 2000). STD has been shown to bestow neuronal networks with functional capabilities such as filtering and gain control to increase their sensitivity to sudden changes (Abbott and Regehr, 2004). Dysfunctioning of STD modulation could

\section{REFERENCES}

Abbott, L. F., and Regehr, W. G. (2004). Synaptic computation. Nature 431, 796-803.

Abraham, W. C. (2008). Metaplasticity: tuning synapses and networks for plasticity. Nat. Rev. Neurosci. 9, 387.

Abraham, W. C., and Tate, W. P. (1997). Metaplasticity: a new vista across the field of synaptic plasticity. Prog. Neurobiol. 52, 303-323.

Becker, C. M. (1990). Disorders of the inhibitory glycine receptor: the spastic mouse. FASEB J. 4, 2767-2774.

Betz, H., and Laube, B. (2006). Glycine receptors: recent insights into their structural organization and functional diversity. J. Neurochem. 97, 1600-1610.

Breivogel, C. S., Griffin, G., Di Marzo, V., and Martin, B. R. (2001). Evidence for a new $G$ protein-coupled cannabinoid receptor in mouse brain. Mol. Pharmacol. 60, 155-163.

Buldakova, S., Real, E., Jakob, Y., and Brezhestovskii, P. (2007). Cadependent modulation of human glycine receptors expressed in cultured cell lines. Tsitologiia 49, 79-82.

Chang, Y., Ghansah, E., Chen, Y., Ye, J., and Weiss, D. S. (2002). Desensitization mechanism of GABA receptors

be of particular relevance in pathophysiology, such as Parkinson's disease (Tecuapetla et al., 2007) and epilepsy (Doherty and Dingledine, 2001).

Thus endocannabinoids enhance the low-pass filtering ability of GlyR synapses for inhibitory signals and consequently increase the probability of transfer of the high-frequency excitatory signals conveyed to hypoglossal neurons. Therefore, endocannabinoids may induce striking changes in the temporal information processing in glycinergic synapses by direct action on postsynaptic GlyRs.

\section{ACKNOWLEDGMENTS}

This study was supported by grants from the European Union Seventh Framework: NEUROCYPRES, HEALTH-F2-2008-202088 (to Natalia Lozovaya, Marat Mukhtarov, and Piotr Bregestovski) and the Marie Curie Fellowship (Natalia Lozovaya), and the FRM grant Nouvelle Equipe (to Nail Burnashev and Natalia Lozovaya).

\section{SUPPLEMENTARY MATERIAL}

The Supplementary Material for this article can be found online at http://www.frontiersin.org/molecular_neuroscience/10.3389/ fnmol.2011.00013/abstract

Figure S1 | Summary of the saturated effects of the modulation of human GlyR $\alpha 1 \mathrm{H}$-mediated currents recorded from outside-out patches by WIN

$\mathbf{5 5 , 2 1 2 - 2}$. (A) Superimposed representative traces of $I_{\text {Gly }}$, induced by $50 \mu \mathrm{M}$ Gly, obtained in control, in the presence of $1 \mu \mathrm{M}$ WIN 55,212-2, and after wash-out of cannabinoids (left). (Middle and right) corresponding traces are normalized. (B) The averaged numbers for changes of $I_{\text {Gi }}$ peak (left), normalized charge (middle), and 10-90\% rise time (right) induced by WIN 55,212-2 plotted as a fraction of the control values.

between facilitation, depression, and residual calcium at three presynaptic terminals. J. Neurosci. 20, 1374 1385.

Dobrunz, L. E., and Stevens, C. F. (1999). Response of hippocampal synapses to natural stimulation patterns. Neuron 22, 157-166.

Doherty, J., and Dingledine, R. (2001). Reduced excitatory drive onto interneurons in the dentate gyrus after status epilepticus. J. Neurosci. 21, 2048-2057.

Fischer, T. M., Blazis, D. E., Priver, N. A., and Carew, T. J. (1997). Metaplasticity at identified inhibitory synapses in Aplysia. Nature 389, 860-865.

Fucile, S., de Saint Jan, D., DavidWatine, B., Korn, H., and Bregestovski, P. (1999). Comparison of glycine and GABA actions on the zebrafish homomeric glycine receptor. J. Physiol. (Lond.) 517(Pt 2), 369-383.

Fucile, S., De Saint Jan, D., Prado de Carvalho, L., and Bregestovski, P. (2000). Fast potentiation of glycine receptor channels by intracellular calcium in neurons and transfected cells. $\mathrm{Neu}$ ron 28, 571-583.

Ge, L. H., Lee, S. C., Liu, J., and Yang, X. L. (2007). Glycine receptors are functionally expressed on bullfrog retinal cone photoreceptors. Neuroscience 146, 427-434.

Grenningloh, G., Pribilla, I., Prior, P., Multhaup, G., Beyreuther, K., Taleb, O., and Betz, H. (1990). Cloning and expression of the $58 \mathrm{kd}$ beta subunit of the inhibitory glycine receptor. Neuron 4 , 963-970.

Grewer, C. (1999). Investigation of the alpha(1)-glycine receptor channelopening kinetics in the submillisecond time domain. Biophys. J. 77, 727-738.

Handford, C. A., Lynch, J. W., Baker, E., Webb, G. C., Ford, J. H., Sutherland, G. R., and Schofield, P. R. (1996). The human glycine receptor beta subunit: primary structure, functional characterisation and chromosomal localisation of the human and murine genes. Brain Res. Mol. Brain Res. 35, 211-219.

Hejazi, N., Zhou, C., Oz, M., Sun, H., Ye, J. H., and Zhang, L. (2006). Delta9-tetrahydrocannabinol and endogenous cannabinoid anandamide directly potentiate the function of glycine receptors. Mol. Pharmacol. 69, 991-997. 
Howlett, A. C., Barth, F., Bonner, T. I., Cabral, G., Casellas, P., Devane, W. A., Felder, C. C., Herkenham, M., Mackie, K., Martin, B. R. Mechoulam, R., and Pertwee, R. G. (2002). International Union of Pharmacology. XXVII. Classification of cannabinoid receptors. Pharmacol. Rev. 54, 161-202.

Iatsenko, N. M., Tsintsadze, T., and Lozova, N. O. (2007). The synthetic cannabinoid analog WIN $55,212-2$ potentiates the amplitudes of glycine-activated currents. Fiziol. Zh. 53, 31-37.

Jones, M. V., and Westbrook, G. L. (1995). Desensitized states prolong GABAA channel responses to brief agonist pulses. Neuron 15, 181-191.

Kano, M., Ohno-Shosaku, T., Hashimotodani, Y., Uchigashima, M., and Watanabe, M. (2009). Endocannabinoid-mediated control of synaptic transmission. Physiol. Rev. 89, 309-380.

Kondratskaya, E. L., Lishko, P. V., Chatterjee, S. S., and Krishtal, O. A. (2002). BN52021, a platelet activating factor antagonist, is a selective blocker of glycine-gated chloride channel. Neurochem. Int. 40, 647-653.

Lagrange, A. H., Botzolakis, E. J., and Macdonald, R. L. (2007). Enhanced macroscopic desensitization shapes the response of alpha4 subtypecontaining GABAA receptors to synaptic and extrasynaptic GABA. J. Physiol. (Lond.) 578, 655-676.

Larkman, A. U., Jack, J. J., and Stratford, K. J. (1997). Quantal analysis of excitatory synapses in rat hippocampal CA1 in vitro during low-frequency depression. J. Physiol. (Lond.) 505(Pt 2), 457-471.

Ledent, C., Valverde, O., Cossu, G., Petitet, F., Aubert, J. F., Beslot, F., Bohme, G. A., Imperato, A., Pedrazzini, T., Roques, B. P., Vassart, G., Fratta, W., and Parmentier, M. (1999). Unresponsiveness to cannabinoids and reduced addictive effects of opiates in $\mathrm{CB} 1$ receptor knockout mice. Science 283, 401404.

Legendre, P. (2001). The glycinergic inhibitory synapse. Cell. Mol. Life Sci. 58, 760-793.

Lozovaya, N., Yatsenko, N., Beketov, A., Tsintsadze, T., and Burnashev, N. (2005). Glycine receptors in CNS neurons as a target for nonretrograde action of cannabinoids. J. Neurosci. 25, 7499-7506.

Lynch, J. W. (2004). Molecular structure and function of the glycine receptor chloride channel. Physiol. Rev. 84, 1051-1095.

Lynch, J. W. (2009). Native glycine receptor subtypes and their physiological roles. Neuropharmacology 56, 303-309.

Lynch, J. W., and Callister, R. J. (2006). Glycine receptors: a new therapeutic target in pain pathways. Curr. Opin. Investig. Drugs 7, 48-53.

Malenka, R. C., and Bear, M. F. (2004). LTP and LTD: an embarrassment of riches. Neuron 44, 5-21.

Markova, O., Mukhtarov, M., Real, E., Jacob, Y., and Bregestovski, P. (2008). Genetically encoded chloride indicator with improved sensitivity. J. Neurosci. Methods 170, 67-76.

Mechoulam, R., Ben-Shabat, S., Hanus, L., Ligumsky, M., Kaminski, N. E., Schatz, A. R., Gopher, A., Almog, S., Martin, B. R., Compton, D. R., Pertweee, R. G., Griffine, G., Bayewitchf, M., Bargf, J., and Vogel, Z. (1995). Identification of an endogenous 2monoglyceride, present in canine gut, that binds to cannabinoid receptors. Biochem. Pharmacol. 50, 83-90.

Medina, I., Krapivinsky, G., Arnold, S., Kovoor, P., Krapivinsky, L., and Clapham, D. E. (2000). A switch mechanism for $\mathrm{G}$ beta gamma activation of I(KACh). J. Biol. Chem. 275, 29709-29716.

Meyer, G., Kirsch, J., Betz, H., and Langosch, D. (1995). Identification of a gephyrin binding motif on the glycine receptor beta subunit. $\mathrm{Neu}$ ron $15,563-572$.

Morales, A., Nguyen, Q. T., and Miledi, R. (1994). Electrophysiological properties of newborn and adult rat spinal cord glycine receptors expressed in Xenopus oocytes. Proc. Natl. Acad. Sci. U.S.A. 91,30973101.

Mukhtarov, M., Ragozzino, D., and Bregestovski, P. (2005). Dual Ca2+ modulation of glycinergic synaptic currents in rodent hypoglossal motoneurones. J. Physiol. (Lond.) $569,817-831$.

Nadim, F., and Manor, Y. (2000). The role of short-term synaptic dynamics in motor control. Curr. Opin. Neurobiol. 10, 683-690.

Nicolelis, M. A. (2002). Depression at thalamocortical synapses: the key for cortical neuronal adaptation? Neuron 34, 331-332.

O’Donovan, M. J., and Rinzel, J. (1997) Synaptic depression: a dynamic regulator of synaptic communication with varied functional roles. Trends Neurosci. 20, 431-433.
Overstreet, L. S., Jones, M. V., and Westbrook, G. L. (2000). Slow desensitization regulates the availability of synaptic GABA(A) receptors. J. Neurosci. 20, 7914-7921.

$\mathrm{Oz}, \mathrm{M}$. (2006). Receptor-independent actions of cannabinoids on cell membranes: focus on endocannabinoids. Pharmacol. Ther. 111, 114144

Peever, J. H., Mateika, J. H., and Duffin, J. (2001). Respiratory control of hypoglossal motoneurones in the rat. Pflugers Arch. 442, 78-86.

Pouille, F., and Scanziani, M. (2004) Routing of spike series by dynamic circuits in the hippocampus. Nature 429, 717-723.

Pribilla, I., Takagi, T., Langosch, D., Bormann, J., and Betz, H. (1992). The atypical M2 segment of the beta subunit confers picrotoxinin resistance to inhibitory glycine receptor channels. EMBO J. 11, 4305-4311.

Rigo, J. M., and Legendre, P. (2006). Frequency-dependent modulation of glycine receptor activation recorded from the zebrafish larvae hindbrain. Neuroscience 140 , 389-402.

Sato, K., Zhang, J. H., Saika, T., Sato, M., Tada, K., and Tohyama, M. (1991). Localization of glycine receptor alpha 1 subunit mRNA-containing neurons in the rat brain: an analysis using in situ hybridization histochemistry. Neuroscience 43, 381395.

Stella, N., Schweitzer, P., and Piomelli, D. (1997). A second endogenous cannabinoid that modulates longterm potentiation. Nature 388,773 778.

Takahashi, T., Momiyama, A., Hirai, K., Hishinuma, F., and Akagi, H. (1992). Functional correlation of fetal and adult forms of glycine receptors with developmental changes in inhibitory synaptic receptor channels. Neuron 9, 1155-1161

Tecuapetla, F., Carrillo-Reid, L., Bargas, J., and Galarraga, E. (2007). Dopaminergic modulation of shortterm synaptic plasticity at striatal inhibitory synapses. Proc. Natl. Acad. Sci. U.S.A. 104, 10258-10263.

Thomas, B. F., Zhang, Y., Brackeen, M. Page, K. M., Mascarella, S. W., and Seltzman, H. H. (2006). Conformational characteristics of the interaction of SR141716A with the CB1 cannabinoid receptor as determined through the use of conformationally constrained analogs. AAPS J. 8 , E665-E671.

Thomson, A. M. (2003). Presynaptic frequency- and pattern-dependent filtering. J. Comput. Neurosci. 15 159-202.

Tsodyks, M. V., and Markram, H. (1997). The neural code between neocortical pyramidal neurons depends on neurotransmitter release probability. Proc. Natl. Acad. Sci. U.S.A. 94, 719-723.

Wassle, H., Heinze, L., Ivanova, E., Majumdar, S., Weiss, J., Harvey, R. J., and Haverkamp, S. (2009). Glycinergic transmission in the Mammalian retina. Front. Mol. Neurosci. 2:6. doi: 10.3389/neuro.02.006.2009

Wassle, H., Koulen, P., Brandstatter, J. H., Fletcher, E. L., and Becker, C. M (1998). Glycine and GABA receptors in the mammalian retina. Vision Res. 38, 1411-1430.

Wilson, R. I., and Nicoll, R. A. (2001). Endogenous cannabinoids mediate retrograde signaling at hippocampal synapses. Nature 410 , 588-592.

Yang, Z., Aubrey, K. R., Alroy, I., Harvey, R. J., Vandenberg, R. J., and Lynch, J. W. (2008). Subunit-specific modulation of glycine receptors by cannabinoids and $\mathrm{N}$-arachidonylglycine. Biochem. Pharmacol. 76, 1014-1023.

Zhang, L., and Xiong, W. (2009). Modulation of the Cys-loop ligandgated ion channels by fatty acid and cannabinoids. Vitam. Horm. 81 , 315-335.

Zucker, R. S., and Regehr, W. G. (2002). Short-term synaptic plasticity. Annu. Rev. Physiol. 64, 355-405.

Conflict of Interest Statement: The authors declare that the research was conducted in the absence of any commercial or financial relationships that could be construed as a potential conflict of interest.

Received: 02 June 2011; accepted: 13 July 2011; published online: 28 July 2011. Citation: Lozovaya N, Mukhtarov $M$, Tsintsadze T, Ledent C, Burnashev $N$ and Bregestovski $P$ (2011) Frequency-dependent cannabinoid receptor-independent modulation of glycine receptors by endocannabinoid 2-AG. Front. Mol. Neurosci. 4:13. doi: 10.3389/fnmol.2011.00013

Copyright (๑) 2011 Lozovaya, Mukhtarov, Tsintsadze, Ledent, Burnashev and Bregestovski. This is an open-access article subject to a non-exclusive license between the authors and Frontiers Media $S A$, which permits use, distribution and reproduction in other forums, provided the original authors and source are credited and other Frontiers conditions are complied with. 


\section{APPENDIX \\ SIMPLIFIED MODEL OF GLYCINE RECEPTOR MODULATION}

The kinetic modeling was performed using the ChannelLab 2.0 software (developed by S. Traynelis for Synaptosoft, Decatur, GA, USA).

Our experimental data indicate that modulation of desensitization may offer a potent mechanism of an amplitude regulation of responses evoked by saturating concentration of glycine. The main goal of model simulation presented here was to consider the impact of desensitization on the amplitude regulation of $I_{\mathrm{Gly}}$ induced by saturating concentration of glycine under condition of high-frequency stimulation.

Taking into account the available experimental evidence, our strategy was to propose a minimum requirement for 2-AG effects by adapting a previously published model (Grewer, 1999; Figure A1). In the model the $k_{4}$ in control conditions was increased, because in the present study the currents elicited by $10 \mathrm{~s}$ pulse of glycine yielded currents with slower decay kinetics, than that predicted by model. The major simplifying assumption of this model is that it postulates only one set of fully bound states (open, closed, desensitized). In particular, it is known that besides unique desensitized state included in the model, there could be several other slower desensitized components which might additionally shape the current responses, especially those elicited by long glycine pulses (Harty and Manis, 1998; Legendre, 1998; Beato et al., 2004).

The major effect of 2-AG was the dramatic acceleration of $I_{\mathrm{Gly}}$ desensitization. At saturating $(1 \mathrm{mM})$ and at $50 \mu \mathrm{m}$ of glycine, 2AG reduced the current amplitude indicating that, as mentioned above, 2-AG favors the occupancy of the desensitized state. As an attempt to model this possibility, we assumed that 2-AG increases the rate constant of entrance into the desensitized state (DL3). Indeed this assumption was sufficient to qualitatively reproduce our experimental finding on acceleration of decay, inhibition of peak amplitude of $I_{\mathrm{Gly}}$ by 2-AG and our main finding: enhancement of frequency-dependent decrease of peak amplitude of $I_{\mathrm{Gly}}$. In addition, 2-AG induces acceleration of $I_{\mathrm{Gly}}$ onset. Such a 2-AG effect can be easily reproduced by increasing the binding rate $k_{2}$ (Tables A1 and A2).

However, our model data are quantitatively slightly contradicted with experimental data: the extent of inhibition of the peak amplitude of $I_{\mathrm{Gly}}$ in train has been more pronounced in model simulation. To adapt our experimental data we had to introduce changes in rate of conformational transition openfully occupied closed state $\left(k_{-4}\right)$. As a matter of fact, the rate of decline of $I_{\mathrm{Gly}}$ reflects both the intrinsic molecular rate constants for desensitization and the probability of occupying states from which desensitization can occur. A perturbation that accelerates the decline of current may do so by increasing either or both

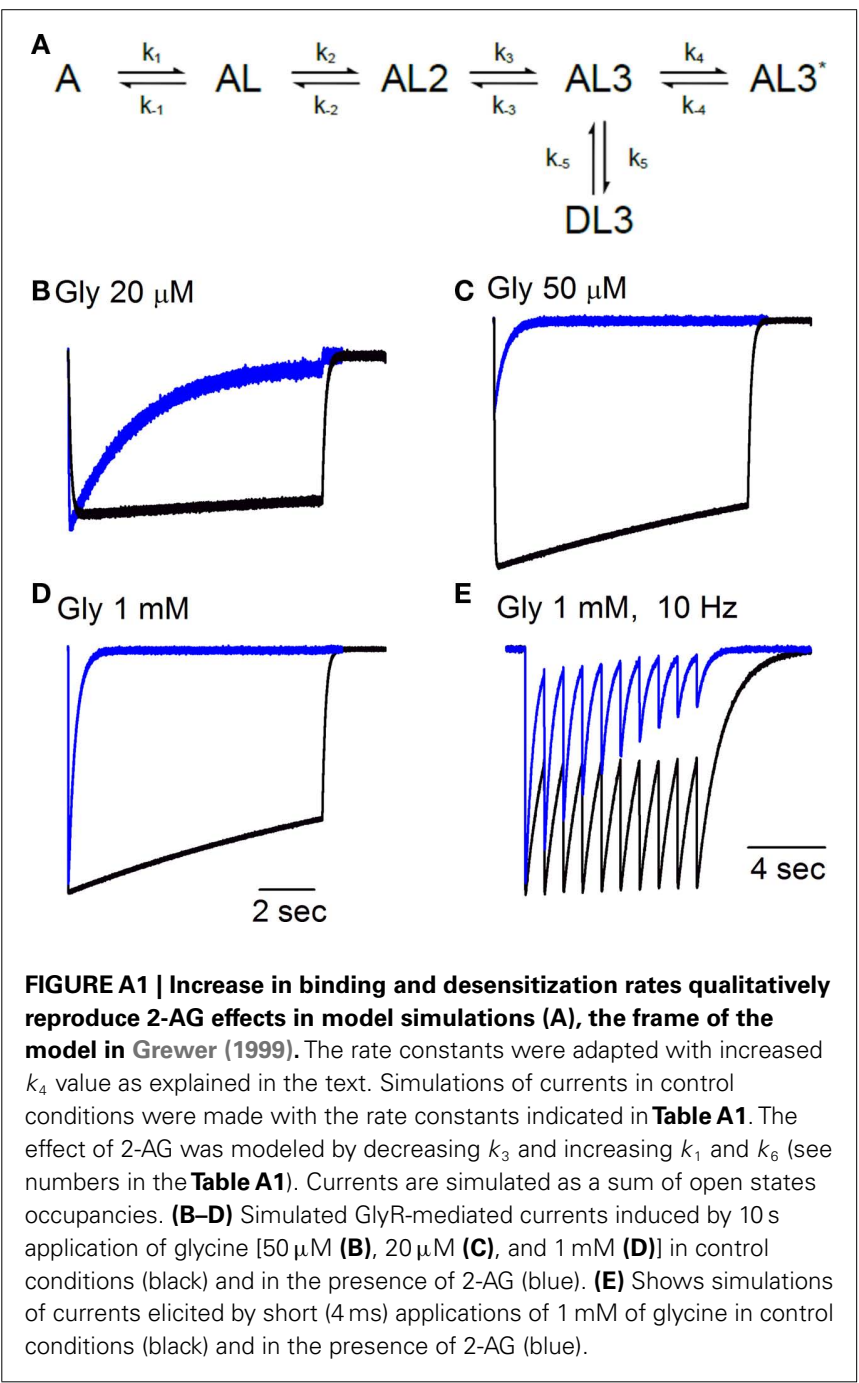

of these processes. The results of simulation are presented in Figures A1B,D.

Nevertheless, to confirm the assumption that 2-AG affect conformational transition open-fully occupied closed state additional single-channel recordings should be performed. On the other hand quantitative contradiction with experimental data can reflect the oversimplification of this model assumptions.

Thus, our model simulations indicate that modulation of GlyR gating by endocannabinoids considered here appears to be most compatible with enhancement of binding and desensitization. Furthermore, these processes mainly account for the strong enhancement of frequency-dependent decrease in GlyR-mediated responses in the presence of $2-\mathrm{AG}$. 
Table A1 | The rate constant values in control conditions and in the presence of 2-AG.

\begin{tabular}{|c|c|c|c|c|c|c|c|c|c|c|c|}
\hline & & $k_{1}\left(\mu M^{-1} s^{-1}\right)$ & $k_{-1}\left(s^{-1}\right)$ & $k_{2}\left(\mu M^{-1} s^{-1}\right)$ & $k_{-2}\left(s^{-1}\right)$ & $k_{3}\left(\mu \mathbf{M}^{-1} \mathbf{s}^{-1}\right)$ & $k_{-} 3\left(s^{-1}\right)$ & $k_{4}\left(s^{-1}\right)$ & $k_{-4}\left(s^{-1}\right)$ & $k_{5}\left(s^{-1}\right)$ & $k_{-5}\left(s^{-1}\right)$ \\
\hline \multicolumn{2}{|c|}{ Control } & 27 & 1900 & 18 & 3800 & 9 & 5700 & $2.2 * 10^{4}$ & 38 & 23.5 & 0.02 \\
\hline [2-AG] & [Gly] & & & & & & & & & & \\
\hline \multirow[t]{3}{*}{$1 \mu \mathrm{M}$} & $20 \mu \mathrm{M}$ & 27 & 1900 & 18 & 350 & 9 & 5700 & $2.2 * 10^{4}$ & 300 & 90 & 0.02 \\
\hline & $50 \mu \mathrm{M}$ & 27 & 1900 & 18 & 350 & 9 & 5700 & $2.2 * 10^{4}$ & 2000 & 90 & 0.02 \\
\hline & $1 \mathrm{mM}$ & 27 & 1900 & 18 & 350 & 9 & 5700 & $2.2 * 10^{4}$ & 100 & 800 & 0.02 \\
\hline
\end{tabular}

Table A2 | The effects of 2-AG $(1 \mu \mathrm{M})$ on $I_{\mathrm{Gly}}$ at different concentration of glycine. ED, experimental data; MS, model simulation.

\begin{tabular}{|c|c|c|c|c|c|c|}
\hline \multirow[t]{2}{*}{ Glycine concentration } & \multicolumn{3}{|c|}{ ED (\%) } & \multicolumn{3}{|c|}{ MS (\%) } \\
\hline & Amplitude & Rise time & Charge & Amplitude & Rise time & Charge \\
\hline $20 \mu \mathrm{M}$ & 104 & 23 & 32.24 & 105.00 & 13.91 & 37 \\
\hline $1 \mathrm{mM}$ & 80 & - & 12.8 & 95 & 93 & 4 \\
\hline
\end{tabular}

\section{REFERENCES}

Beato, M., Groot-Kormelink, P. J., Colquhoun, D., and Sivilotti, L. G. (2004). The activation mechanism of alphal homomeric glycine receptors. J. Neurosci. 24, 895-906.

Harty, T. P., and Manis, P. B. (1998). Kinetic analysis of glycine receptor currents in ventral cochlear nucleus. J. Neurophysiol. 79, 1891-1901.

Legendre, P. (1998). A reluctant gating mode of glycine receptor channels determines the time course of inhibitory miniature synaptic events in zebrafish hindbrain neurons. J. Neurosci. 18, 2856-2870. 